\title{
Teor de proteínas nos grãos em resposta à aplicação de nitrogênio em diferentes estádios de desenvolvimento da cevada
}

\author{
Protein content in barley seeds affected by nitrogen application in different growth stages
}

\author{
Anderson Fernando Wamser ${ }^{\mathrm{I}}$ Claudio Mario Mundstock ${ }^{\mathrm{II}}$
}

\section{RESUMO}

\begin{abstract}
O presente trabalho teve como objetivo avaliar o teor de proteínas em grãos de cevada em resposta à aplicação de $N$ em estádios de desenvolvimento da cultura. Os experimentos foram conduzidos em Eldorado do Sul e Encruzilhada do Sul, no ano de 2000, e em Victor Graeff, nos anos de 2000 e 2001, em delineamento experimental em blocos casualizados com quatro repetições. Os estádios de aplicação de $N$ foram na emergência das plântulas; na emissão da $2^{\underline{a}}$ ou $3^{\underline{a}}$ folha; da $4^{\underline{a}}$ ou $5^{\underline{a}}$ folha; $6^{\underline{a}}$ ou $7^{7 \underline{a}}$ folha; $8^{\underline{a}}$ ou $9^{\underline{a}}$ folha; e no emborrachamento. As doses de $N$ foram de 30 ou $40 \mathrm{~kg} \mathrm{ha}^{-1}$ e 60 ou $80 \mathrm{~kg} \mathrm{ha}^{-1}$, para a menor e maior dose, respectivamente. As determinações realizadas foram teor de proteínas nos grãos e número de grãos metro-2. Para os experimentos realizados em 2000, a aplicação de nitrogênio até o início do alongamento dos entrenós (emissão da 7a folha) manteve o teor de proteínas no grão abaixo dos $12 \%$, mesmo para a maior dose de $N$. Os teores de proteínas no grão em Victor Graeff, no ano de 2001, ficaram acima do limite máximo de $12 \%$ com a aplicação da maior dose de $N$ já em estádios iniciais de desenvolvimento da cultura, devido ao maior teor de matéria orgânica no solo em relação aos outros locais.
\end{abstract}

Palavras-chave: Hordeum vulgare L., manejo do nitrogênio, qualidade de grãos.

\section{ABSTRACT}

This study was was aimed at evaluating the protein content in barley seeds affected by nitrogen application in different growth stages. Experiments were carried out in Eldorado do Sul and Encruzilhada do Sul, in 2000, and Victor Graeff, in 2000 and 2001, on a randomized blocks scheme with four repetitions. The growth stages of $N$ application were in emergency of seedlings; emission of $2^{\text {nd }}$ or $3^{\text {rd }}$ leaf; $4^{\text {th }}$ or $5^{\text {th }}$ leaf; $6^{\text {th }}$ or $7^{\text {th }}$ leaf; $8^{\text {th }}$ or $9^{\text {th }}$ leaf; and in boot stage. The $N$ rates were 30 or $40 \mathrm{~kg} \mathrm{ha}^{-1}$ and 60 or $80 \mathrm{~kg} \mathrm{ha}^{-1}$, for smallest and largest $N$ rate, respectively. The protein content in barley seeds and the number of grains area ${ }^{-1}$ were determined. In the experiments carried out in 2000 the nitrogen application until the beginning of the internodes elongation maintained the seeds protein content below of $12 \%$, inclusive in the largest $N$ rate. The seeds protein content in Victor Graeff, 2001, surpassed the maximum limit of $12 \%$ with $N$ applications in initial growth stages, decurrently of the higher soil organic matter content in relation to others experiments.

Key words: Hordeum vulgare L., nitrogen management, grains quality.

\section{INTRODUÇÃO}

A qualidade de grãos de cevada para a produção de malte é prejudicada quando o teor de proteínas no grão ultrapassa $12 \%$. Valores acima deste teor acabam diminuindo o rendimento (PERUZZO et al., 1996) e a qualidade de malte cervejeiro (QI et al., 2005). O excesso de proteínas no grão resulta em menor teor de amido e, conseqüentemente, de carboidratos fermentescíveis (FLORIANI, 2002). A menor quantidade de carboidratos aumenta o tempo de maltagem para que ocorram as modificações necessárias neste processo. Além disso, o excesso de proteínas no grão aumenta as quantidades de proteínas solúveis no malte e no mosto, resultando em cerveja de baixa estabilidade (FLORIANI, 2002).

\footnotetext{
IEstação Experimental de Caçador, Empresa de Pesquisa Agropecuária e Extensão Rural de Santa Catarina (EPAGRI). Rua Abílio Franco, 1500, Bairro Bom Sucesso, CP 591, 89500-000, Caçador, SC, Brasil. E-mail: afwamser@epagri.sc.gov.br. Autor para correspondência.

IIDepartamento de Plantas de Lavoura, Faculdade de Agronomia, Universidade Federal do Rio Grande do Sul (UFRGS). Av. Bento Gonçalves, 7712, CP 776, 91540-000, Porto Alegre, RS, Brasil.
} 
A quantidade e a época de aplicação de nitrogênio (N) são as principais práticas de manejo que afetam o teor de proteínas no grão em cevada. De forma geral, o aumento da quantidade de $\mathrm{N}$ aplicado (LAUER \& PARTRIDGE, 1990; MCTAGGART \& SMITH, 1995) e o atraso da época de aplicação de N (EASSON, 1984; ZEBARTH \& SHEARD, 1992; BULMAN \& SMITH, 1993) aumentam os teores de proteínas no grão dos cereais de estação fria. Em relação à época de aplicação de N, ZEBARTH \& SHEARD (1992) e BULMAN \& SMITH (1993) encontraram maior teor de proteínas no grão com a aplicação de N no alongamento dos entrenós em relação à aplicação no início do afilhamento, enquanto que EASSON (1984) só observou incrementos a partir da emissão da folha bandeira.

A Sociedade Brasileira de Ciência do Solo recomenda a adubação nitrogenada em cobertura, para a cevada cervejeira, preferencialmente no início do afilhamento, não devendo ser aplicada após o alongamento dos colmos (SOCIEDADE BRASILEIRA DE CIÊNCIA DO SOLO, 2004). Entretanto, em outros cereais de estação fria, como aveia (MUNDSTOCK \& BREDEMEIER, 2001) e trigo (BREDEMEIER \& MUNDSTOCK, 2001), foram observados aumentos no rendimento de grãos com a aplicação tardia de $\mathrm{N}$ no final do afilhamento e início do alongamento dos colmos. Este aumento está ligado à maior taxa de sobrevivência dos afilhos (MUNDSTOCK \& BREDEMEIER, 2001), resultando em maior número de espigas e, conseqüentemente, em maior número de grãos área-1 . O aumento do número de espigas e grãos área $^{-1}$, com a aplicação tardia de $\mathrm{N}$, pode proporcionar maior diluição do $\mathrm{N}$ da parte vegetativa entre essas estruturas, resultando em reduzido incremento nos teores de proteínas no grão.

O presente trabalho teve como objetivos avaliar o teor de proteínas em grãos de cevada em resposta à aplicação de $\mathrm{N}$ em diferentes estádios de desenvolvimento da cultura e verificar a possibilidade de atrasar a aplicação de $\mathrm{N}$ em cobertura, a partir da emissão da $6^{\text {a }}$ folha do colmo principal ou no início do alongamento dos colmos, sem comprometer a qualidade dos grãos para a indústria cervejeira.

\section{MATERIAL E MÉTODOS}

Os experimentos foram realizados na Estação Experimental Agronômica da Universidade Federal do Rio Grande do Sul (EEA/UFRGS), município de Eldorado do Sul (RS), no Campo Experimental de Cevada da Companhia Brasileira de Bebidas (CEC/ AmBev), município de Encruzilhada do Sul (RS), e no Campo Experimental Norte da Companhia Brasileira de
Bebidas (CEN/AmBev), município de Victor Graeff(RS), no ano de 2000, e um experimento foi realizado em 2001, no CEN/AmBev. Os solos das áreas experimentais de Eldorado do Sul, Victor Graeff e Encruzilhada do Sul foram caracterizados como Argissolo Vermelho distrófico típico, Latossolo Vermelho distrófico típico e Argissolo Vermelho-amarelo distrófico típico, respectivamente (EMBRAPA, 1999). Os atributos químicos dos solos das áreas experimentais se encontram na tabela 1 .

Os tratamentos consistiram na combinação de seis épocas de aplicação e duas doses de $\mathrm{N}$ na forma de uréia. As aplicações de $\mathrm{N}$ foram realizadas de acordo com a escala de desenvolvimento do colmo principal proposta por HAUN (1973), nos estádios 0.1

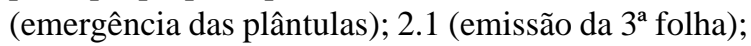
4.1 (emissão da 5 a folha); 6.1 (emissão da 7a folha); 8.1 (emissão da 9a folha) e emborrachamento. No experimento conduzido em Victor Graeff, no ano de 2001, as épocas de aplicação de $\mathrm{N}$ foram os estádios 0.1 (emergência das plântulas); 1.1 (emissão da 2a folha); 3.1 (emissão da 4 - folha); 5.1 (emissão da $6^{\mathrm{a}}$ folha); 7.1 (emissão da 8a folha) e emborrachamento. Em Victor Graeff, no ano de 2000, não houve aplicação de N por ocasião da emissão da 3a folha (3.1 da escala Haun). Em Eldorado do Sul, as doses testadas de N foram 40 e $80 \mathrm{~kg} \mathrm{ha}^{-1}$. Em Encruzilhada do Sul e em Victor Graeff, utilizaram-se as doses de 30 e $60 \mathrm{~kg} \mathrm{ha}^{-1}$. A menor dose de $\mathrm{N}$ foi aplicada de forma única nos seis estádios de desenvolvimento. A maior dose de $\mathrm{N}$ foi aplicada de forma única nos seis estádios de desenvolvimento ou parcelada, sendo 40 ou $30 \mathrm{~kg} \mathrm{ha}^{-1}$ no momento da emergência e 40 ou $30 \mathrm{~kg} \mathrm{ha}^{-1}$ nos demais estádios de desenvolvimento. Em todos os locais foi utilizado um tratamento controle, sem aplicação de N.

A cultivar de cevada utilizada em todos os locais foi a “MN 698”, com ciclo de 140 dias (90 dias da semeadura ao espigamento), estatura de $70-80 \mathrm{~cm}$ e moderada resistência ao acamamento (CAIERÃO \& SPEROTTO, 2006). A semeadura foi realizada nos dias 23/06/2000 em Eldorado do Sul, 18/05/2000 e 31/05/2001 em Victor Graeff, e 18/07/2000 em Encruzilhada do Sul. Utilizou-se uma semeadora de plantio direto, colocando-se as sementes em linha na densidade de 250 sementes aptas metro ${ }^{-2}$. As culturas antecessoras foram milho em Eldorado do Sul e soja em Encruzilhada do Sul e Victor Graeff.

A adubação de base foi com fósforo e potássio, aplicados na linha, nas formas de superfosfato triplo e cloreto de potássio, respectivamente, nas doses de $90 \mathrm{~kg} \mathrm{ha}^{-1} \mathrm{de}_{2} \mathrm{P}_{2} \mathrm{O}_{5}$ e $45 \mathrm{~kg}$ ha $^{-1}$ de $\mathrm{K}_{2} \mathrm{O}$, em Eldorado do Sul, e $50 \mathrm{~kg} \mathrm{ha}^{-1}$ de $\mathrm{P}_{2} \mathrm{O}_{5}$ e $60 \mathrm{~kg} \mathrm{ha}^{-1}$ de $\mathrm{K}_{2} \mathrm{O}$ em Encruzilhada do Sul e Victor Graeff. 
Teor de proteínas nos grãos em resposta à aplicação de nitrogênio em diferentes estádios de desenvolvimento...

Tabela 1 - Potencial hidrogeniônico $(\mathrm{pH})$, fósforo (P), potássio $(\mathrm{K})$, matéria orgânica $(\mathrm{MO})$, alumínio $\left(\mathrm{Al}^{3+}\right)$, cálcio $\left(\mathrm{Ca}^{2+}\right)$, magnésio $\left(\mathrm{Mg}^{2+}\right)$ e saturação de bases (V) dos solos de amostras retiradas antes da instalação dos experimentos.

\begin{tabular}{|c|c|c|c|c|c|c|c|c|c|}
\hline Ano & Local $^{(1)}$ & $\mathrm{pH}\left(\mathrm{H}_{2} \mathrm{O}\right)$ & P (Mehlich-1) & K (Mehlich-1) & $\mathrm{MO}^{(2)}$ & $\mathrm{Al}^{3+}$ & $\mathrm{Ca}^{2+}$ & $\mathrm{Mg}^{2+}$ & $\mathrm{V}$ \\
\hline & & & ---------------mg & $\mathrm{m}^{-3}$-------------- & $\mathrm{gkg}^{-1}$ & ------ & $\operatorname{mol}_{\mathrm{C}} \mathrm{dn}$ & -------- & $\%$ \\
\hline \multirow[t]{3}{*}{2000} & EEA & 5,3 & 6,6 & 238 & 21 (B) & 0,1 & 3,9 & 1,5 & 56 \\
\hline & CEN & 5,6 & 26,0 & $>202$ & $38(\mathrm{M})$ & 0,1 & 5,4 & 2,5 & 70 \\
\hline & CEC & 5,4 & 47,0 & 160 & 23 (B) & 0,1 & 4,6 & 1,5 & 63 \\
\hline 2001 & CEN & 6,0 & $>52,0$ & $>202$ & $45(\mathrm{M})$ & 0,1 & 7,0 & 3,4 & 80 \\
\hline
\end{tabular}

${ }^{(1)}$ EEA = Estação Experimental Agronômica da Universidade Federal do Rio Grande do Sul (UFRGS), município de Eldorado do Sul (RS); CEN = Campo Experimental Norte da Companhia Brasileira de Bebidas (AmBev), município de Victor Graeff $(\mathrm{RS})$; CEC = Campo Experimental de Cevada da Companhia Brasileira de Bebidas (AmBev), município de Encruzilhada do Sul (RS).

${ }^{(2)}$ Interpretação do teor de MO no solo: B = baixo; $\mathrm{M}$ = médio (SOCIEDADE BRASILEIRA DE CIÊNCIA DO SOLO, 2004).

As demais práticas de manejo foram realizadas de acordo com as Recomendações da Comissão de Pesquisa de Cevada para o cultivo de cevada cervejeira em 1999 e 2000 (COMISSÃO DE PESQUISA DE CEVADA, 1999).

O delineamento experimental utilizado foi em blocos casualizados com quatro repetições. A área das unidades experimentais foi constituída por 11 linhas de $5 \mathrm{~m}$ de comprimento e espaçadas em $17 \mathrm{~cm}$. A área útil das unidades experimentais, onde se procedeu à colheita final de grãos, constituiu-se das sete linhas centrais, descartando-se $0,5 \mathrm{~m}$ em cada extremidade das linhas. Retirou-se uma amostra de $20 \mathrm{~g}$ de grãos, a partir da massa total de grãos obtida em cada unidade experimental, para determinação do teor de proteína no grão. A determinação do teor de nitrogênio no grão foi realizada pelo método Kjeldahl, conforme descrito por TEDESCO et al. (1995). O teor de proteínas no grão foi obtido utilizando o fator de correção de 6,25, sendo realizado em duas duplicatas. O número de grãos metro ${ }^{-2}$ foi avaliado através dos componentes do rendimento número de espigas metro ${ }^{-2}$ e número de grãos espiga ${ }^{-1}$. O número de espigas metro ${ }^{-2}$ foi determinado antes da colheita, através da contagem do número de espigas em quatro metros da linha central da área útil de cada parcela. O número de grãos por espiga foi determinado através da razão entre o peso total de grãos da área útil e o produto do número de espigas da área útil e a massa média de grão. As variáveis estudadas foram submetidas à análise de variância pelo teste F.

\section{RESULTADOS E DISCUSSÃO}

Os teores médios de proteínas no grão foram de 10,5, 10,3, 10,5 e 12,0\%, para Eldorado do Sul, Encruzilhada do Sul e Victor Graeff em 2000, e Victor Graeff em 2001, respectivamente. Os teores médios de proteínas no grão observados em 2000 estão próximos ao teor ótimo, que é de $10 \%$, conforme BAIL \&
MEYNARD (2003). Para locais de cultivo, houve diferenças significativas entre os tratamentos $(\mathrm{P} \leq 0,05)$. O teor de proteínas no grão aumentou com aplicações mais tardias de N (Figura 1), sendo similar aos resultados observados por EASSON (1984), ZEBARTH \& SHEARD (1992) e BULMAN \& SMITH (1993). Entretanto, em Victor Graeff, em 2001, os teores de proteínas ultrapassaram o máximo aceitável nas aplicações das maiores doses de $\mathrm{N}$, seja em aplicação única ou parcelada, já a partir da emissão da 2 a folha (Figura 1d). Esta resposta pode ser resultado do alto suprimento de $\mathrm{N}$ pelo solo, em função do maior teor de matéria orgânica (4,5\%) em relação às outras áreas. Porém, salienta-se que a maior dose de $\mathrm{N}$ utilizada nesta área $\left(60 \mathrm{~kg} \mathrm{ha}^{-1}\right)$ foi superior ao recomendado pelas indicações técnicas (30 kg ha-1), tendo a soja como cultura antecessora (SOCIEDADE BRASILEIRA DE CIÊNCIA DO SOLO, 2004), o que também contribuiu para elevar o teor de proteínas no grão acima do aceitável.

Em Eldorado do Sul e Encruzilhada do Sul, somente a partir da emissão da 9a folha a aplicação da maior dose de $\mathrm{N}$ resultou em aumento nos teores de proteínas no grão acima do permitido pela indústria cervejeira (Figuras 1a e 1b). Em Victor Graeff, no ano de 2000 , foi observado teor acima de $12 \%$ somente com a aplicação da maior dose de $\mathrm{N}$ no emborrachamento (Figura 1c). Entretanto, para a aplicação da menor dose de $\mathrm{N}$ nestas áreas, os aumentos nos teores de proteínas no grão, com as aplicações tardias de $\mathrm{N}$, não ultrapassaram o máximo aceitável. Estes resultados estão de acordo com os obtidos por LAUER \& PARTRIDGE (1990) e MCTAGGART \& SMITH (1995), que observaram maiores teores de proteínas no grão com o aumento das doses de N. Quando a maior dose de $\mathrm{N}$ foi aplicada de forma parcelada, houve menor teor de proteínas no grão em relação à aplicação única, principalmente nas aplicações mais tardias de N, sendo que para Eldorado do Sul, Encruzilhada do Sul e Victor 


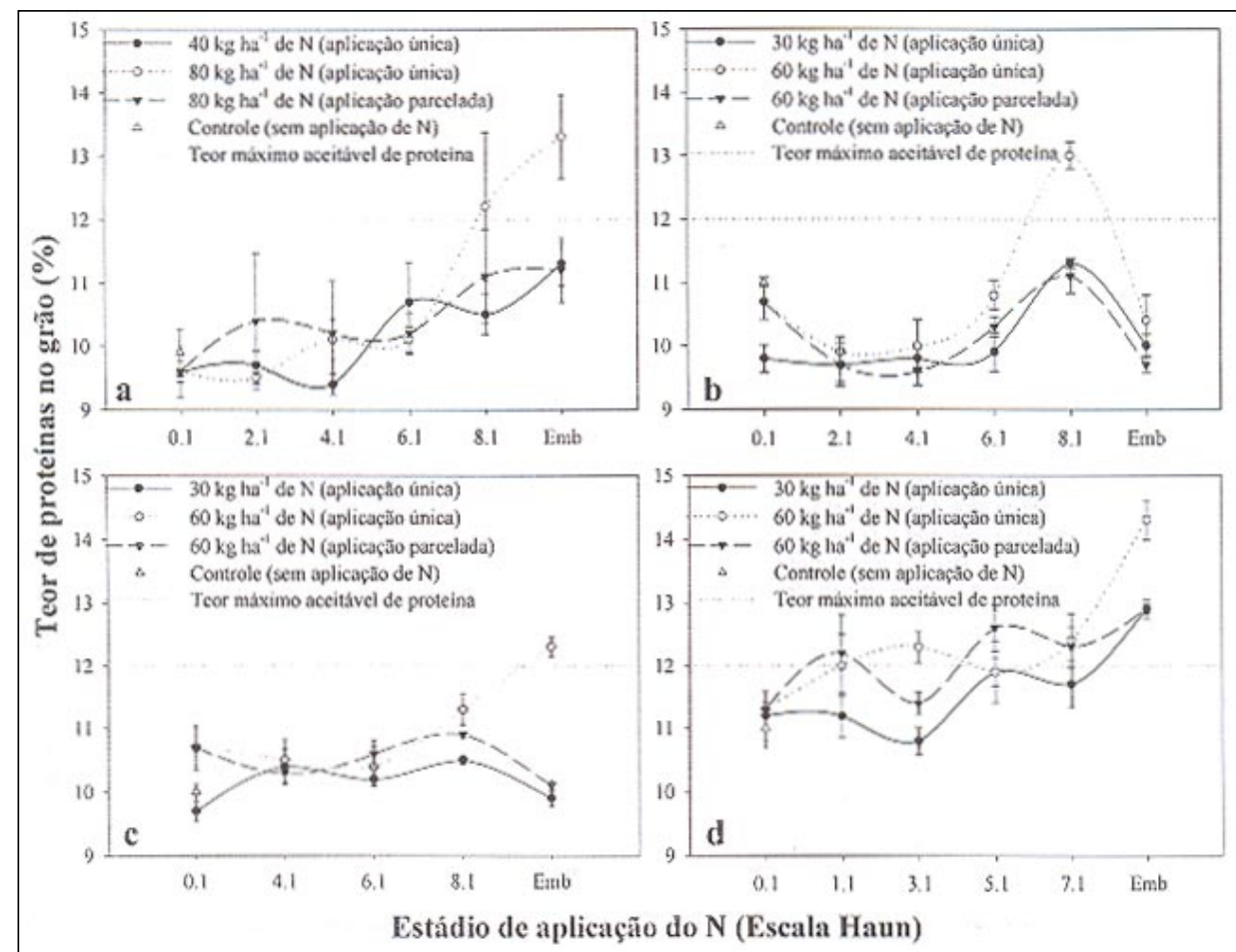

Figura 1 - Teor de proteínas em grãos de cevada em resposta à aplicação de $\mathrm{N}$ em seis estádios da cultura em (a) Eldorado do Sul, 2000; (b) Encruzilhada do Sul, 2000; (c) Victor Graeff, 2000; (d) Victor Graeff, 2001. Barras verticais representam o erro padrão da média.

Graeff, em 2000, os teores ficaram abaixo dos $12 \%$ e foram semelhantes à aplicação única da menor dose.

Os teores máximos de proteínas no grão foram observados com a aplicação única da maior dose na emissão da 9a folha, em Encruzilhada do Sul (Figura 1b), e no emborrachamento, em Eldorado do Sul e Victor Graeff, em 2000 e 2001 (Figuras 1a, 1c e 1d). O alto teor de proteínas com a aplicação de $\mathrm{N}$ nestes estádios possivelmente se deve ao elevado acúmulo de $\mathrm{N}$ na planta, sem resultar em acréscimos no número de grãos área ${ }^{-1}$, como mostram os resultados obtidos em Eldorado do Sul (Figura 2). Desta forma, há maior disponibilidade de $\mathrm{N}$ para o enchimento de um menor número de grãos. $\mathrm{O}$ decréscimo do teor de proteínas no grão com a aplicação de N no emborrachamento, em Encruzilhada do Sul, ao contrário dos outros locais, provavelmente se deve à redução da absorção de $\mathrm{N}$ do solo, visto que o acúmulo de $\mathrm{N}$ e biomassa pelos cereais de estação fria começam a estagnar a partir deste estádio (PRZULJ \& MOMCILOVIC, 2003).

Para Eldorado do Sul, Encruzilhada do Sul e Victor Graeff, em 2000, as aplicações de N na emissão

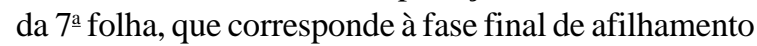
e início do alongamento dos entrenós, proporcionaram baixos teores de proteínas no grão, similares às aplicações de $\mathrm{N}$ no início do ciclo. O baixo teor de proteínas no grão com a aplicação tardia de $\mathrm{N}$ no início do alongamento dos colmos pode ser atribuído ao incremento do número de grãos metro-2 ${ }^{-2}$ conforme observado em Eldorado do Sul (Figura 2). Este aumento permitiu maior diluição do $\mathrm{N}$ presente nas estruturas vegetativas entre as estruturas reprodutivas, mantendo os teores de proteínas no grão em níveis abaixo do máximo permitido. Estes dados mostram que é possível atrasar a adubação de $\mathrm{N}$ em cobertura para o final do afilhamento, visando ao aumento do rendimento de grãos, conforme observado para outros cereais de estação fria (MUNDSTOCK \& BREDEMEIER, 2001; BREDEMEIER \& MUNDSTOCK, 2001), sem que o incremento do teor de proteínas ultrapasse o teor máximo aceitável à qualidade cervejeira.

\section{CONCLUSÃO}

A aplicação de doses recomendadas de $\mathrm{N}$ até o início do alongamento dos entrenós, ou emissão da 6 a folha do colmo principal, não incrementa o teor de proteínas em grãos de cevada acima dos $12 \%$, permitindo a aplicação de $\mathrm{N}$ neste estádio.

\section{AGRADECIMENTOS E APRESENTAÇÃO}

Ao Conselho Nacional de Desenvolvimento Científico e Tecnológico (CNPq) e à Companhia Brasileira de Bebidas (AmBev), pelo apoio financeiro dado ao trabalho. 


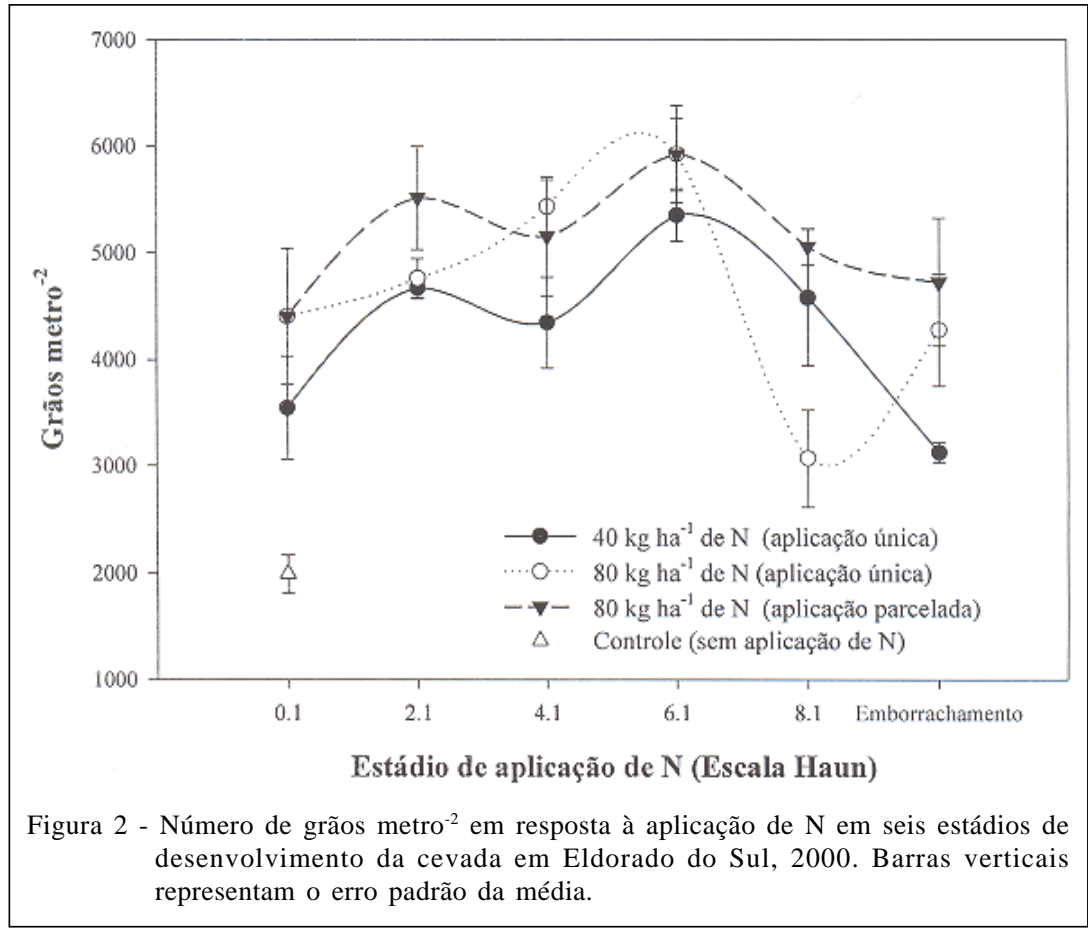

Parte da Dissertação de Mestrado apresentada pelo primeiro autor ao Programa de Pós-graduação em Fitotecnia da Universidade Federal do Rio Grande do Sul - UFRGS, Porto Alegre, RS, Brasil.

\section{REFERENNCIAS}

BAIL, M.; MEYNARD, J.M. Yield and protein concentration of spring malting barley: the effects of cropping systems in the Paris Basin (France). Agronomie, Versailles, v.23, n.1, p.1327, 2003

BREDEMEIER, C.; MUNDSTOCK, C.M. Estádios fenológicos do trigo para a adubação nitrogenada em cobertura. Revista Brasileira de Ciência do Solo, Campinas, v.25, n.2, p.317323, 2001.

BULMAN, P.; SMITH, D.L. Grain protein response of spring barley to high rates and post-anthesis application of fertilizer nitrogen. Agronomy Journal, Madison, v.85, n.6, p.11091113, 1993

CAIERÃO, E.; SPEROTTO, A.L. Barley cultivar MN 698, high malting quality for the state of Rio Grande do Sul. Ciência Rural, Santa Maria, v.36, n.1, p.279-281, 2006.

COMISSÃO DE PESQUISA DE CEVADA. Recomendações técnicas da Comissão de Pesquisa de Cevada para o cultivo de cevada cervejeira em 1999 e 2000. Passo Fundo: Embrapa Trigo, 1999. V.1, 71p.

EASSON, D.L. The timing of nitrogen application for spring barley. Journal of Agricultural Science, Cambridge, v.102, n.3, p.673-678, 1984.
EMBRAPA. Centro Nacional de Pesquisa de Solos. Sistema brasileiro de classificação de solos. Brasília: EMBRAPA, 1999. 412p.

FLORIANI, A.P. Cevada cervejeira: características bioquímicas. UFRGS, Porto Alegre, maio 2002. Capturado em 09 mar. 2006. Online. Disponível na Internet http://www.ufrgs.br/ Alimentus/feira/mpcerea/cevada\%20cervejeira/t\%20bioqui.htm.

HAUN, J.R. Visual quantification of wheat development. Agronomy Journal, Madison, v.65, n.1, p.116-119, 1973.

LAUER, J.G.; PARTRIDGE, J.R. Planting date and nitrogen rate effects on spring malting barley. Agronomy Journal, Madison, v.82, n.6, p.1083-1088, 1990.

McTAGGART, I.P.; SMITH, K.A. The effect of rate, form and timing of fertilizer $\mathrm{N}$ on nitrogen uptake and grain $\mathrm{N}$ content in spring malting barley. Journal of Agricultural Science, Cambridge, v.125, n.3, p.341-353, 1995.

MUNDSTOCK, C.M.; BREDEMEIER, C. Disponibilidade de nitrogênio e sua relação com o afilhamento e o rendimento de grãos de aveia. Ciência Rural, Santa Maria, v.31, n.2, p.205211, 2001

PERUZZO, G. et al. Efeito do nitrogênio na cultura da cevada, 1993. In: REUNIÃO ANUAL DE PESQUISA DE CEVADA, 14., 1994, Passo Fundo. Resultados de pesquisa de cevada. Passo Fundo: Embrapa Trigo, 1996. p.65-68.

PRZULJ, N.; MOMCILOVIC, V. Dry matter and nitrogen accumulation and use in spring barley. Plant Soil and Environment, Praha, v.49, n.1, p.36-47, 2003. 
QI, J. et al. Protein and hordein fraction content in barley seeds as affected by sowing date and their relations to malting quality. Journal of Zhejiang University Science B, Hangzhou, v.6, n.11, p.1069-1075, 2005.

SOCIEDADE BRASILEIRA DE CIÊNCIA DO SOLO. Comissão de Química e Fertilidade do Solo. Manual de adubação e calagem para os estados do Rio Grande do Sul e de Santa Catarina. Porto Alegre: Comissão de Química e Fertilidade do Solo, 2004. 400p.
TEDESCO, M.J. et al. Análises de solo, plantas e outros materiais. 2.ed. Porto Alegre: Departamento de Solos da UFRGS, 1995. 174p. (Boletim Técnico de Solos, 5).

ZEBARTH, B.J.; SHEARD, R.W. Influence of rate and timing of nitrogen fertilization on yield and quality of hard red winter wheat in Ontario. Canadian Journal of Plant Science, Ottawa, v.72, n.1 p.13-19, 1992. 